Article

\title{
The Acoustic Properties of Water Submerged Lodgepole Pine (Pinus contorta) and Spruce (Picea spp.) Wood and Their Suitability for Use as Musical Instruments
}

\author{
Calvin Hilde ${ }^{1}$, Renata Woodward ${ }^{2}$, Stavros Avramidis ${ }^{3}$ and Ian D. Hartley ${ }^{2, *}$ \\ 1 Department of Physics, University of Northern British Columbia, 3333 University Way, \\ Prince George, BC V2N 4Z9, Canada; E-Mail: calvin.hilde@unbc.ca \\ 2 Ecosystem Science and Management Program, University of Northern British Columbia, \\ 3333 University Way, Prince George, BC V2N 4Z9, Canada; \\ E-Mail: renata.woodward@alumni.unbc.ca \\ 3 Department of Wood Science, the University of British Columbia, 2424 Main Mall, Vancouver, \\ BC V6T 1Z4, Canada; E-Mail: stavros.avramidis@ubc.ca \\ * Author to whom correspondence should be addressed; E-Mail: ian.hartley@unbc.ca; \\ Tel.: +1-250-960-6054; Fax: +1-250-960-5539.
}

Received: 25 September 2013; in revised form: 5 February 2014 / Accepted: 14 July 2014 / Published: 6 August 2014

\begin{abstract}
Wood is a common material used for the manufacture of many products, and submerged wood, in particular, has been used in niche markets and musical instruments. In order to examine if submerged wood in British Columbia, Canada, would be appropriate for use as musical instruments, a study was performed in 2007 on submerged wood from Ootsa Lake, British Columbia, Canada. The results of that study showed the wood was not suitable for musical instruments. In this paper, the wood samples were allowed to age untouched in a laboratory setting and were then retested under the hypothesis that physical acoustic characteristics would improve. It was shown, however, that acoustic properties became less adequate after being left to dry over time. This article describes the density, speed of sound, acoustic constant and characteristic impedance properties for submerged wood and a comparison is made for different applications for musical instruments.
\end{abstract}

Keywords: wood; acoustic constant; characteristic impedance; submerged wood 


\section{Introduction}

Wood is used in component manufacturing for musical instruments such as guitars, bagpipes, xylophones, pianos, organs and violins. The resonance characteristics of different wood species have been studied, including how to improve its acoustical characteristics, and why some wood species are more suitable than others [1]. The selection of wood has traditionally fallen upon experienced instrument makers who choose wood for maximum aesthetic and acoustical quality. Some other key wood characteristics include: absence of imperfections (i.e., knots), lack of compression wood, no fungal attacks, suitable ring width and colour.

Despite the development of alternatives to wood-based products, solid wood remains the source in the manufacturing of many chordophones such as guitars, violins and pianos; aerophones, such as the oboe or bagpipes; and percussion instruments such as xylophones and drums. However, due to the non-homogeneous nature of wood, there is a large variation in properties between wood species [1] as well as between individual samples within a species that can impact the acoustic properties. Spruce, for example, is a common material in building soundboards for violins and guitars [2], due to its resonant properties [3-5].

Determining if wood is acoustically suitable is sometimes performed through physical means such as listening to the resonance [6]. The usual tap test is not an easy process to implement on a large-scale manufacturing of instruments. It is possible, however, to look at the physical acoustic characteristics and define what characteristics that may be required for different types of instruments.

Wood that is fully submerged in water remains in an anaerobic state and will not face attack from fungi, due to the lack of oxygen. While it is still susceptible to long-term degradation due to micro-bacterial attack, the preservation of wood from other types of degradation while under water makes submerged wood a viable supply of wood for industry. Recovered submerged wood is often used in niche markets such as for veneers for flooring [7], by local artisans for their products [7] as well as for use in the manufacturing of musical instruments [8].

In a previous experiment [2], submerged wood was tested to determine the suitability for musical instruments. The samples were obtained from Ootsa Lake, British Columbia, Canada. They were cut into circular disks and then further separated into samples with approximate dimensions of $55 \mathrm{~mm} \times 15 \mathrm{~mm} \times$ $15 \mathrm{~mm}$. In that study, the wood was shown not to be suitable for musical instruments based on the acoustic constant. However, it was believed that the physical acoustic constants may improve after being allowed to age in a laboratory setting, similar to the one used for high quality musical instruments [1]. In this study, results of the acoustic measurements on the same submerged wood samples were analyzed and comparisons were made to known and accepted values of both common and resonant wood samples.

\section{Results and Discussion}

\subsection{Speed of Sound}

The speed of sound, $c_{\text {ave }}$, for each disk in the 2010 data set was found to be lower compared with the 2007 data sets (Table 1). Comparing the pine and spruce samples separately showed a larger decrease in $c$ of the spruce samples from 2007 to 2010 than there was for the pine samples. The difference of $c_{\text {ave }}$ for spruce was $\sim 780 \mathrm{~m} \cdot \mathrm{s}^{-1}$ while the difference in $c_{\text {ave }}$ for pine was $\sim 440 \mathrm{~m} \cdot \mathrm{s}^{-1}$; 
the differences were statistically significant. It is known that the $c$ will decrease as $M C$ increases [9]. For 2007 data set, the wood was $M C=12 \%$ and for the 2010 data set, the wood was $M C=6 \%$. Therefore, the speed of sound for the 2010 data set should have been higher compared to the 2007 data set. However, the reverse was observed.

Table 1. Results for speed of sound measurements.

\begin{tabular}{|c|c|c|c|c|c|c|c|}
\hline \multirow{2}{*}{\multicolumn{2}{|c|}{ Disk—Data Set }} & \multirow[t]{2}{*}{$c_{a v e}\left(\mathbf{m} \cdot \mathbf{s}^{-1}\right)$} & \multirow{2}{*}{$\begin{array}{l}\text { St. Dev. } \\
-\end{array}$} & \multirow[t]{2}{*}{$\delta c$} & \multicolumn{3}{|c|}{ Welch Two Sample $t$-test } \\
\hline & & & & & t-stat & $v$ & $p$-value \\
\hline \multicolumn{8}{|c|}{ Pine } \\
\hline \multirow{2}{*}{1} & 2010 & 2540 & 207 & 40 & \multirow{2}{*}{-6.21} & \multirow{2}{*}{52} & \multirow{2}{*}{$9.17 \times 10^{-08}$} \\
\hline & 2007 & 2910 & 222 & 40 & & & \\
\hline \multirow{2}{*}{2} & 2010 & 2670 & 174 & 30 & \multirow{2}{*}{-9.31} & \multirow{2}{*}{56} & \multirow{2}{*}{$5.82 \times 10^{-13}$} \\
\hline & 2007 & 3090 & 168 & 30 & & & \\
\hline \multirow{2}{*}{3} & 2010 & 2680 & 135 & 30 & \multirow{2}{*}{-9.08} & \multirow{2}{*}{46} & \multirow{2}{*}{$8.77 \times 10^{-12}$} \\
\hline & 2007 & 3100 & 200 & 30 & & & \\
\hline \multirow{2}{*}{4} & 2010 & 2520 & 195 & 40 & \multirow{2}{*}{-9.49} & \multirow{2}{*}{52} & \multirow{2}{*}{$6.58 \times 10^{-13}$} \\
\hline & 2007 & 3102 & 281 & 50 & & & \\
\hline \multirow{2}{*}{5} & 2010 & 2560 & 198 & 40 & \multirow{2}{*}{-8.06} & \multirow{2}{*}{62} & \multirow{2}{*}{$3.33 \times 10^{-11}$} \\
\hline & 2007 & 2990 & 217 & 40 & & & \\
\hline \multirow{2}{*}{7} & 2010 & 2670 & 214 & 40 & \multirow{2}{*}{-4.96} & \multirow{2}{*}{52} & $700 \times 10^{-06}$ \\
\hline & 2007 & 3000 & 286 & 50 & & & $1.99 \times 10$ \\
\hline All Pine & 2010 & 2600 & 201 & 20 & & & $-22 \times 0^{-16}$ \\
\hline (Average) & 2007 & 3040 & 245 & 20 & -11.91 & 353 & $<2.2 \times 0$ \\
\hline & & & Spru & & & & \\
\hline 6 & 2010 & 2440 & 183 & 30 & -1263 & 49 & $<22 \times 10^{-16}$ \\
\hline 0 & 2007 & 3230 & 288 & 50 & 12.05 & 47 & $-2.2 \times 10$ \\
\hline 8 & 2010 & 2580 & 193 & 30 & -1528 & 64 & $<2.2 \times 10^{-16}$ \\
\hline 0 & 2007 & 3340 & 204 & 40 & 10.20 & (ד & $2.2 \times 10$ \\
\hline 0 & 2010 & 2590 & 165 & 30 & -1819 & 59 & $<22 \times 10^{-16}$ \\
\hline 3 & 2007 & 3500 & 237 & 40 & 10.17 & S & $-2.2 \times 10$ \\
\hline 10 & 2010 & 2530 & 199 & 30 & -13.01 & 67 & $<22 \times 10^{-16}$ \\
\hline & 2007 & 3230 & 251 & 30 & -15.01 & $0 /$ & \\
\hline 11 & 2010 & 2560 & 182 & 40 & -1201 & 17 & $5.70 \times 10^{-16}$ \\
\hline 11 & 2007 & 3270 & 233 & 50 & -12.01 & 41 & $5.10 \times 10$ \\
\hline All Spruce & 2010 & 2540 & 207 & 40 & -2991 & 289 & $<2.2 \times 10^{-16}$ \\
\hline (Average) & 2007 & 3320 & 265 & 20 & 29.91 & 209 & $-2.2 \times 10$ \\
\hline All Samples & 2010 & 2570 & 200 & 10 & -3087 & 588 & $<22 \times 10^{-1}$ \\
\hline (Average) & 2007 & 3170 & 291 & 20 & -50.01 & 500 & $-2.2 \times 10$ \\
\hline
\end{tabular}

A high speed of sound is required for most resonant wood. In general, a $c>3000 \mathrm{~m} \cdot \mathrm{s}^{-1}$ is required while a speed of sound between 4000 and $6500 \mathrm{~m} \cdot \mathrm{s}^{-1}$ is preferred for soundboards [10]. For spruce, a $c_{\text {ave }}=5600 \mathrm{~m} \cdot \mathrm{s}^{-1}$ (with a range $5200-6300 \mathrm{~m} \cdot \mathrm{s}^{-1}$ ) is chosen for musical instruments is appropriate [11] and $c_{\text {ave }}$ for pine is $3500 \mathrm{~m} \cdot \mathrm{s}^{-1}$ [12].

In this study, both data sets were below the minimum requirements in soundboard applications. The largest measurement for the 2010 and 2007 data sets were 3050 and $3930 \mathrm{~m} \cdot \mathrm{s}^{-1}$, respectively. 
In addition, the $c$ for the wood samples measured in 2010 , were all lower than $3500 \mathrm{~m} \cdot \mathrm{s}^{-1}$, the $c_{\text {ave }}$ for pine [12]. This was in contrast to the 2007 data set in which both spruce and pine had values within the average range, with the average for the spruce disks being within the normal range.

\subsection{Density}

There was a statistical difference for density between the two data sets. With the exception of Disk 7 , ( $p$-value of 0.882), every disk showed a statistically significant difference between the two sets of measurements (95\% confidence level) (Table 2). Also, between the data sets in a species group, the density values were significantly different. A decrease in density occurred for each with a difference in $\rho_{\text {ave }}$ for pine of $\sim 27 \mathrm{~kg} \cdot \mathrm{m}^{-3}$ and for spruce of $\sim 24 \mathrm{~kg} \cdot \mathrm{m}^{-3}$. Overall, the two data sets were statistically different with the 2010 data set being lower than the 2007 data, likely attributed to the lower moisture content.

Table 2. Results for density measurements.

\begin{tabular}{|c|c|c|c|c|c|c|c|}
\hline \multirow{2}{*}{\multicolumn{2}{|c|}{ Disk-Data Set }} & \multirow{2}{*}{$\rho\left(\mathrm{kg} \cdot \mathrm{m}^{3}\right)$} & \multirow{2}{*}{$\begin{array}{l}\text { St. Dev. } \\
- \\
\end{array}$} & \multirow[t]{2}{*}{$\delta \rho$} & \multicolumn{3}{|c|}{ Welch Two Sample $t$-test } \\
\hline & & & & & $t$-stat & $v$ & $p$-value \\
\hline \multicolumn{8}{|c|}{ Pine } \\
\hline \multirow{2}{*}{1} & 2010 & 470 & 32 & 6 & \multirow{2}{*}{-3.03} & \multirow{2}{*}{52} & \multirow{2}{*}{$3.84 \times 10^{-03}$} \\
\hline & 2007 & 496 & 29 & 6 & & & \\
\hline \multirow{2}{*}{2} & 2010 & 450 & 30 & 5 & \multirow{2}{*}{-4.45} & \multirow{2}{*}{50} & \multirow{2}{*}{$4.90 \times 10^{-05}$} \\
\hline & 2007 & 480 & 20 & 4 & & & \\
\hline \multirow{2}{*}{3} & 2010 & 508 & 26 & 5 & \multirow{2}{*}{-3.39} & \multirow{2}{*}{52} & \multirow{2}{*}{$1.34 \times 10^{-03}$} \\
\hline & 2007 & 532 & 24 & 5 & & & \\
\hline \multirow{2}{*}{4} & 2010 & 464 & 38 & 7 & \multirow{2}{*}{-4.16} & \multirow{2}{*}{58} & \multirow{2}{*}{$1.05 \times 10^{-04}$} \\
\hline & 2007 & 507 & 39 & 7 & & & \\
\hline \multirow{2}{*}{5} & 2010 & 433 & 41 & 7 & \multirow{2}{*}{-3.06} & \multirow{2}{*}{61} & \multirow{2}{*}{$3.32 \times 10^{-03}$} \\
\hline & 2007 & 466 & 45 & 8 & & & \\
\hline \multirow{2}{*}{7} & 2010 & 508 & 52 & 10 & \multirow{2}{*}{-0.15} & \multirow{2}{*}{56} & 0887 \\
\hline & 2007 & 510 & 54 & 10 & & & 0.882 \\
\hline All Pine & 2010 & 471 & 47 & 4 & -516 & 344 & $028 \times 10^{-08}$ \\
\hline (Average) & 2007 & 498 & 43 & 3 & -3.40 & 344 & $9.20 \times 10$ \\
\hline & & & Spr & & & & \\
\hline 6 & 2010 & 393 & 22 & 4 & -542 & 58 & $122 \times 10^{-06}$ \\
\hline 0 & 2007 & 425 & 23 & 4 & -5.42 & 58 & $1.22 \times 10$ \\
\hline 8 & 2010 & 335 & 14 & 2 & -413 & 63 & $108 \times 10^{-04}$ \\
\hline 0 & 2007 & 351 & 16 & 2 & -4.15 & 03 & $1.00 \times 10$ \\
\hline 9 & 2010 & 429 & 14 & 2 & -349 & 64 & $872 \times 10^{-04}$ \\
\hline & 2007 & 442 & 17 & 3 & -5.49 & & \\
\hline 10 & 2010 & 386 & 33 & 6 & -388 & 70 & $233 \times 10^{-04}$ \\
\hline & 2007 & 418 & 36 & 6 & -3.88 & & $2.33 \times 10$ \\
\hline 11 & 2010 & 363 & 31 & 6 & -280 & 50 & $720 \times 10^{-03}$ \\
\hline 11 & 2007 & 389 & 33 & 7 & -2.80 & 50 & $1.29 \times 10$ \\
\hline All Spruce & 2010 & 382 & 40 & 3 & -512 & 315 & $536 \times 10^{-07}$ \\
\hline (Average) & 2007 & 406 & 42 & 3 & -5.12 & 315 & $3.36 \times 10$ \\
\hline All Samples & 2010 & 429 & 62 & 3 & -517 & 664 & $316 \times 10^{-}$ \\
\hline (Average) & 2007 & 454 & 63 & 3 & -5.17 & 664 & \\
\hline
\end{tabular}


The desired density required for different musical instruments range between 300 and $1400 \mathrm{~kg} \cdot \mathrm{m}^{-3}$. For soundboards, a lower density is preferred, between 320 and $530 \mathrm{~kg} \cdot \mathrm{m}^{-3}$ [10] whereas a narrower range has been identified for spruce between 440 and $480 \mathrm{~kg} \cdot \mathrm{m}^{-3}$ [11]. Standing lodgepole pine has a density between 400 and $450 \mathrm{~kg} \cdot \mathrm{m}^{-3}$, while spruce have density between 266 and $518 \mathrm{~kg} \cdot \mathrm{m}^{-3}$ (Engelmann spruce) and 257 and $540 \mathrm{~kg} \cdot \mathrm{m}^{-3}$ (white spruce) [13]. In this study, the $\rho_{\text {ave }}$ values for both the 2007 and 2010 data sets were within the range of values preferred for resonant wood. The pine samples had a higher density and maximum range than the spruce samples for both data sets; both data sets had values for pine that were above normal range of resonant wood. The densities of the spruce samples, however, were below $530 \mathrm{~kg} \cdot \mathrm{m}^{-3}$ [10] and $480 \mathrm{~kg} \cdot \mathrm{m}^{-3}$ [11] for the 2010 data set. The spruce samples in the 2007 data set were within normal ranges for resonant wood, although the largest measurement was $486 \mathrm{~kg} \cdot \mathrm{m}^{-3}$ which was higher than the maximum $480 \mathrm{~kg} \cdot \mathrm{m}^{-3}$ [11].

\subsection{Acoustic Constant}

There was a statistically significant difference between the two data sets for acoustic constant, $A C$, for each disk, for each species, and all the samples combined (Table 3). This was expected because there was a significant difference for $c$ and for all, but one for $\rho$. There was a larger decrease in $A C$ for the spruce samples compared to the pine samples. The spruce samples changed from $8.27 \pm 0.09$ to $6.72 \pm 0.07 \mathrm{~m}^{4} \cdot \mathrm{kg}^{-1} \cdot \mathrm{s}^{-1}$ (a decrease of $1.55 \mathrm{~m}^{4} \cdot \mathrm{kg}^{-1} \cdot \mathrm{s}^{-1}$ ) whereas the pine $A C$ changed from $6.13 \pm 0.04$ to $5.56 \pm 0.04 \mathrm{~m}^{4} \cdot \mathrm{kg}^{-1} \cdot \mathrm{s}^{-1}$ (a decrease of $0.57 \mathrm{~m}^{4} \cdot \mathrm{kg}^{-1} \cdot \mathrm{s}^{-1}$ ).

Higher $A C$ values are preferred for musical instruments, primarily for soundboards that require a high speed of sound and a low density, leading to preferred values between 9 and $16 \mathrm{~m}^{4} \cdot \mathrm{kg}^{-1} \cdot \mathrm{s}^{-1}$ [10]. Wood for other instruments, such as xylophone bars or violin bows, have $A C$ between 4 and $8 \mathrm{~m}^{4} \cdot \mathrm{kg}^{-1} \cdot \mathrm{s}^{-1}[10]$. Recently, $A C$ values of 11.15 and $10.67 \mathrm{~m}^{4} \cdot \mathrm{kg}^{-1} \cdot \mathrm{s}^{-1}$ were determined for Interior spruce from British Columbia [3].

The $A C_{\text {ave }}$ values for pine, spruce, and for all the samples combined were below $9 \mathrm{~m}^{4} \cdot \mathrm{kg}^{-1} \cdot \mathrm{s}^{-1}$, including error, indicating that none of the disks would be suitable for soundboards. Additionally, the $A C_{\max }$ was $9.53 \mathrm{~m}^{4} \cdot \mathrm{kg}^{-1} \cdot \mathrm{s}^{-1}$ which was slightly above the minimum acceptable $A C$. The 2007 data set had values within the range of resonant wood (Table 3); the $A C_{\max }$ for spruce was $9.53 \mathrm{~m}^{4} \cdot \mathrm{kg}^{-1} \cdot \mathrm{s}^{-1}$ and Disk 8 falls mostly within the range of resonant woods. Although the $A C$ obtained were not appropriate for soundboards, the wood may be appropriate xylophones, violin bows, and other types of instruments meeting the minimum value of $4 \mathrm{~m}^{4} \cdot \mathrm{kg}^{-1} \cdot \mathrm{s}^{-1}[10]$.

Table 3. Results for acoustic constant measurements.

\begin{tabular}{|c|c|c|c|c|c|c|c|}
\hline \multirow{2}{*}{\multicolumn{2}{|c|}{ Disk-Data Set }} & \multirow{2}{*}{$A C_{a v e}\left(\mathrm{~m}^{4} \cdot \mathrm{kg}^{-1} \cdot \mathrm{s}^{-1}\right)$} & \multirow{2}{*}{ St. Dev. } & \multirow[t]{2}{*}{$\delta A C$} & \multicolumn{3}{|c|}{ Welch Two Sample $t$-test } \\
\hline & & & & & \multirow{2}{*}{$t$-stat } & \multirow[t]{2}{*}{$v$} & \multirow{2}{*}{$p$-value } \\
\hline & & & Pine & & & & \\
\hline \multirow{2}{*}{1} & 2010 & 5.41 & 0.46 & 0.09 & \multirow{2}{*}{-3.43} & \multirow{2}{*}{51} & \multirow{2}{*}{$1.22 \times 10^{-03}$} \\
\hline & 2007 & 5.89 & 0.53 & 0.10 & & & \\
\hline \multirow{2}{*}{2} & 2010 & 5.95 & 0.58 & 0.10 & \multirow{2}{*}{-3.77} & \multirow{2}{*}{49} & \multirow{2}{*}{$4.45 \times 10^{-04}$} \\
\hline & 2007 & 6.45 & 0.39 & 0.07 & & & \\
\hline \multirow{2}{*}{3} & 2010 & 5.28 & 0.38 & 0.07 & \multirow{2}{*}{-5.11} & \multirow{2}{*}{51} & \multirow{2}{*}{$4.73 \times 10^{-06}$} \\
\hline & 2007 & 5.85 & 0.42 & 0.08 & & & \\
\hline \multirow{2}{*}{4} & 2010 & 5.44 & 0.42 & 0.08 & \multirow{2}{*}{-6.96} & \multirow{2}{*}{57} & \multirow{2}{*}{$3.58 \times 10^{-09}$} \\
\hline & 2007 & 6.16 & 0.37 & 0.07 & & & \\
\hline
\end{tabular}


Table 3. Cont.

\begin{tabular}{|c|c|c|c|c|c|c|c|}
\hline \multirow{2}{*}{\multicolumn{2}{|c|}{ Disk-Data Set }} & \multirow{2}{*}{$A C_{a v e}\left(\mathrm{~m}^{4} \cdot \mathrm{kg}^{-1} \cdot \mathrm{s}^{-1}\right)$} & \multirow{2}{*}{ St. Dev. } & \multirow[t]{2}{*}{$\delta A C$} & \multicolumn{3}{|c|}{ Welch Two Sample $t$-test } \\
\hline & & & & & t-stat & $v$ & $p$-value \\
\hline \multicolumn{8}{|c|}{$\begin{array}{c}\text { Pine } \\
\end{array}$} \\
\hline \multirow{2}{*}{5} & 2010 & 5.95 & 0.50 & 0.09 & \multirow{2}{*}{-4.01} & \multirow{2}{*}{61} & \multirow{2}{*}{$1.70 \times 10^{-04}$} \\
\hline & 2007 & 6.44 & 0.45 & 0.08 & & & \\
\hline \multirow{2}{*}{7} & 2010 & 5.27 & 0.34 & 0.06 & \multirow{2}{*}{-5.60} & \multirow{2}{*}{49} & \multirow{2}{*}{$9.48 \times 10^{-07}$} \\
\hline & 2007 & 5.91 & 0.50 & 0.09 & & & \\
\hline \multirow{2}{*}{$\begin{array}{l}\text { All Pine } \\
\text { (Average) }\end{array}$} & 2010 & 5.56 & 0.54 & 0.04 & \multirow{2}{*}{-29.91} & \multirow{2}{*}{289} & \multirow{2}{*}{$<2.2 \times 10^{-16}$} \\
\hline & 2007 & 6.13 & 0.51 & 0.04 & & & \\
\hline \multicolumn{8}{|c|}{ Spruce } \\
\hline \multirow{2}{*}{6} & 2010 & 6.22 & 0.67 & 0.1 & \multirow{2}{*}{-6.64} & \multirow{2}{*}{52} & \multirow{2}{*}{$1.77 \times 10^{-08}$} \\
\hline & 2007 & 7.65 & 0.94 & 0.2 & & & \\
\hline \multirow{2}{*}{8} & 2010 & 7.71 & 0.61 & 0.1 & \multirow{2}{*}{-12.38} & \multirow{2}{*}{64} & \multirow{2}{*}{$<2.2 \times 10^{-16}$} \\
\hline & 2007 & 9.53 & 0.57 & 0.1 & & & \\
\hline \multirow{2}{*}{9} & 2010 & 6.04 & 0.41 & 0.07 & \multirow{2}{*}{-14.78} & \multirow{2}{*}{57} & \multirow{2}{*}{$<2.2 \times 10^{-16}$} \\
\hline & 2007 & 7.94 & 0.61 & 0.1 & & & \\
\hline \multirow{2}{*}{10} & 2010 & 6.61 & 0.85 & 0.1 & \multirow{2}{*}{-5.48} & 60 & $643 \times 10^{-07}$ \\
\hline & 2007 & 7.80 & 0.97 & 0.2 & & 09 & $0.43 \times 10$ \\
\hline 11 & 2010 & 7.09 & 0.56 & 0.1 & -657 & 12 & $623 \times 10^{-08}$ \\
\hline 11 & 2007 & 8.48 & 0.90 & 0.2 & -6.57 & 42 & $6.23 \times 10$ \\
\hline All Spruce & 2010 & 6.72 & 0.89 & 0.07 & & & $20 \times 10^{-16}$ \\
\hline (Average) & 2007 & 8.27 & 1.07 & 0.09 & -17.97 & 333 & $<2.2 \times 10$ \\
\hline All Samples & 2010 & 6.12 & 0.93 & 0.05 & 2007 & 500 & $=20 \times$ \\
\hline (Average) & 2007 & 7.15 & 1.35 & 0.07 & -30.81 & 588 & $<2.2 \times 10$ \\
\hline
\end{tabular}

\subsection{Characteristic Impedance}

The characteristic impedance, $Z$, is an important value for musical instruments, particularly for string instruments $[1,10]$ often requiring soundboards to have a low characteristic impedance. By contrast, percussion instruments, such as xylophones, require higher characteristic impedance so that resonance will be for a longer period of time [10]. For soundboards, a $Z$ value of between 1.2 and $3.392 \mathrm{MPa} \mathrm{s} \cdot \mathrm{m}^{-1}$ is required and between 1.68 and $5.76 \mathrm{MPa} \mathrm{s} \cdot \mathrm{m}^{-1}$ for woodwind instruments and xylophones [10].

From this study, the characteristic impedance was lower in the 2010 data set compared to the 2007 data set for every disk and for both pine and spruce (Table 4). These differences were statistically significant and, more specifically, the $Z_{\text {ave }}$ for spruce was lower than that of pine for both sets of data. This was expected since the $\rho$ and $c$ were lower in the 2010 data set.

For the 2010 data set, the $Z_{\text {ave }}$ value for spruce was below the accepted value for soundboards. However, the highest value was $1.26 \mathrm{MPa} \cdot \mathrm{s} \cdot \mathrm{m}^{-1}$ which is within the required range. The pine samples were within range of both soundboards and wood for use in other instruments but were lower than $1.57 \mathrm{MPa} \cdot \mathrm{s} \cdot \mathrm{m}^{-1}$ as reported by others [12]. The whole 2007 data set, by contrast, had values appropriate for both soundboards and other instruments. 
Table 4. Results for characteristic impedance calculations.

\begin{tabular}{|c|c|c|c|c|c|c|c|}
\hline \multirow{2}{*}{\multicolumn{2}{|c|}{ Disk-Data Set }} & \multirow[t]{2}{*}{$Z_{a v e}\left(\mathrm{MPa} \cdot \mathbf{s} \cdot \mathrm{m}^{-1}\right)$} & \multirow{2}{*}{$\begin{array}{l}\text { St. Dev. } \\
- \\
\end{array}$} & \multirow[t]{2}{*}{$\delta Z$} & \multicolumn{3}{|c|}{ Welch Two Sample $t$-test } \\
\hline & & & & & \multirow[t]{2}{*}{$t$-stat } & \multirow[t]{2}{*}{$v$} & \multirow[t]{2}{*}{$p$-value } \\
\hline & & & Pine & & & & \\
\hline \multirow{2}{*}{1} & 2010 & 1.20 & 0.15 & 0.03 & \multirow{2}{*}{-6.05} & \multirow{2}{*}{52} & \multirow{2}{*}{$1.58 \times 10^{-07}$} \\
\hline & 2007 & 1.44 & 0.15 & 0.03 & & & \\
\hline \multirow{2}{*}{2} & 2010 & 1.20 & 0.11 & 0.02 & \multirow{2}{*}{-9.65} & \multirow{2}{*}{56} & \multirow{2}{*}{$1.66 \times 10^{-13}$} \\
\hline & 2007 & 1.49 & 0.11 & 0.02 & & & \\
\hline \multirow{2}{*}{3} & 2010 & 1.36 & 0.10 & 0.02 & \multirow{2}{*}{-8.74} & \multirow{2}{*}{46} & \multirow{2}{*}{$2.44 \times 10^{-11}$} \\
\hline & 2007 & 1.65 & 0.14 & 0.03 & & & \\
\hline \multirow{2}{*}{4} & 2010 & 1.17 & 0.16 & 0.03 & \multirow{2}{*}{-7.76} & \multirow{2}{*}{51} & \multirow{2}{*}{$3.46 \times 10^{-10}$} \\
\hline & 2007 & 1.59 & 0.24 & 0.04 & & & \\
\hline \multirow{2}{*}{5} & 2010 & 1.11 & 0.16 & 0.03 & \multirow{2}{*}{-5.94} & \multirow{2}{*}{57} & \multirow{2}{*}{$1.75 \times 10^{-07}$} \\
\hline & 2007 & 1.40 & 0.22 & 0.04 & & & \\
\hline \multirow{2}{*}{7} & 2010 & 1.36 & 0.23 & 0.04 & & & \\
\hline & 2007 & 1.54 & 0.27 & 0.05 & -2.66 & 55 & $1.02 \times 10^{-0 z}$ \\
\hline All Pine & 2010 & 1.23 & 0.18 & 0.01 & -2201 & 283 & $22 \times 10^{-16}$ \\
\hline (Average) & 2007 & 1.52 & 0.22 & 0.01 & -22.01 & 283 & $<2.2 \times 10$ \\
\hline & & & Spruce & & & & \\
\hline & 2010 & 0.96 & 0.07 & 0.01 & & & $29 \times 10^{-16}$ \\
\hline 6 & 2007 & 1.37 & 0.11 & 0.02 & -17.48 & 49 & $<2.2 \times 10$ \\
\hline 8 & 2010 & 0.87 & 0.08 & 0.01 & -1308 & 50 & $<22 \times 10^{-16}$ \\
\hline 8 & 2007 & 1.17 & 0.11 & 0.02 & -13.08 & 59 & $<2.2 \times 10$ \\
\hline & 2010 & 1.11 & 0.08 & 0.01 & & & $<22 \times 10^{-16}$ \\
\hline 9 & 2007 & 1.55 & 0.12 & 0.02 & -17.48 & 59 & \\
\hline 10 & 2010 & 0.98 & 0.11 & 0.02 & -1282 & 65 & $<22 \times 10^{-16}$ \\
\hline 10 & 2007 & 1.35 & 0.14 & 0.02 & -12.82 & 65 & $<2.2 \times 10$ \\
\hline 11 & 2010 & 0.93 & 0.12 & 0.02 & & 49 & $309 \times 10^{-12}$ \\
\hline 11 & 2007 & 1.27 & 0.14 & 0.03 & -9.18 & 49 & $3.09 \times 10$ \\
\hline All Spruce & 2010 & 0.97 & 0.12 & 0.01 & 327 & & $<22 \times 10^{-16}$ \\
\hline (Average) & 2007 & 1.35 & 0.18 & 0.01 & -13.27 & 388 & $<2.2 \times 10^{-10}$ \\
\hline All samples & 2010 & 1.11 & 0.20 & 0.01 & ח 20 & 662 & $<22 \times 10^{-16}$ \\
\hline (Average) & 2007 & 1.44 & 0.22 & 0.01 & -20.20 & 662 & $<2.2 \times 10$ \\
\hline
\end{tabular}

\subsection{Compared Properties}

By plotting the density against the speed of sound on a logarithmic scale, known as a material property chart [10], it was possible to show how the submerged wood compared to appropriate $A C$ and $Z$ values for resonant woods. The accepted values for soundboards are represented by the grey and green rectangles in Figure 1a. The 2010 data set is in the accepted area. The submerged wood had a range of densities that was comparable to that of soundboards, but had noticeably lower $c$ values. Based on this comparison (Figure 1a), the submerged wood did not have suitable speed of sound values and, consequently, did not have suitable $A C$ values compared to soundboards. The slope of the $A C$ line in Figure $1 \mathrm{~b}$ showed the pine and spruce samples were suitable for other musical instruments [1]. Despite having an appropriate $A C$ for other instruments, the $Z$ value was not found to be within range of appropriate values for other instruments (Figure 1b). The submerged pine samples, however, were found to be within the range of appropriate $Z$ values for soundboards even though the $A C$ values were 
not (Figure 1a). Since the submerged pine and spruce samples have either $A C$ or $Z$ that are too low for soundboards or other instruments, it can be concluded that neither is appropriate for use as resonant wood.

Figure 1. Speed vs. density scatterplot with acoustic constant (a) and with impedance (b). Note: logarithmic scales.

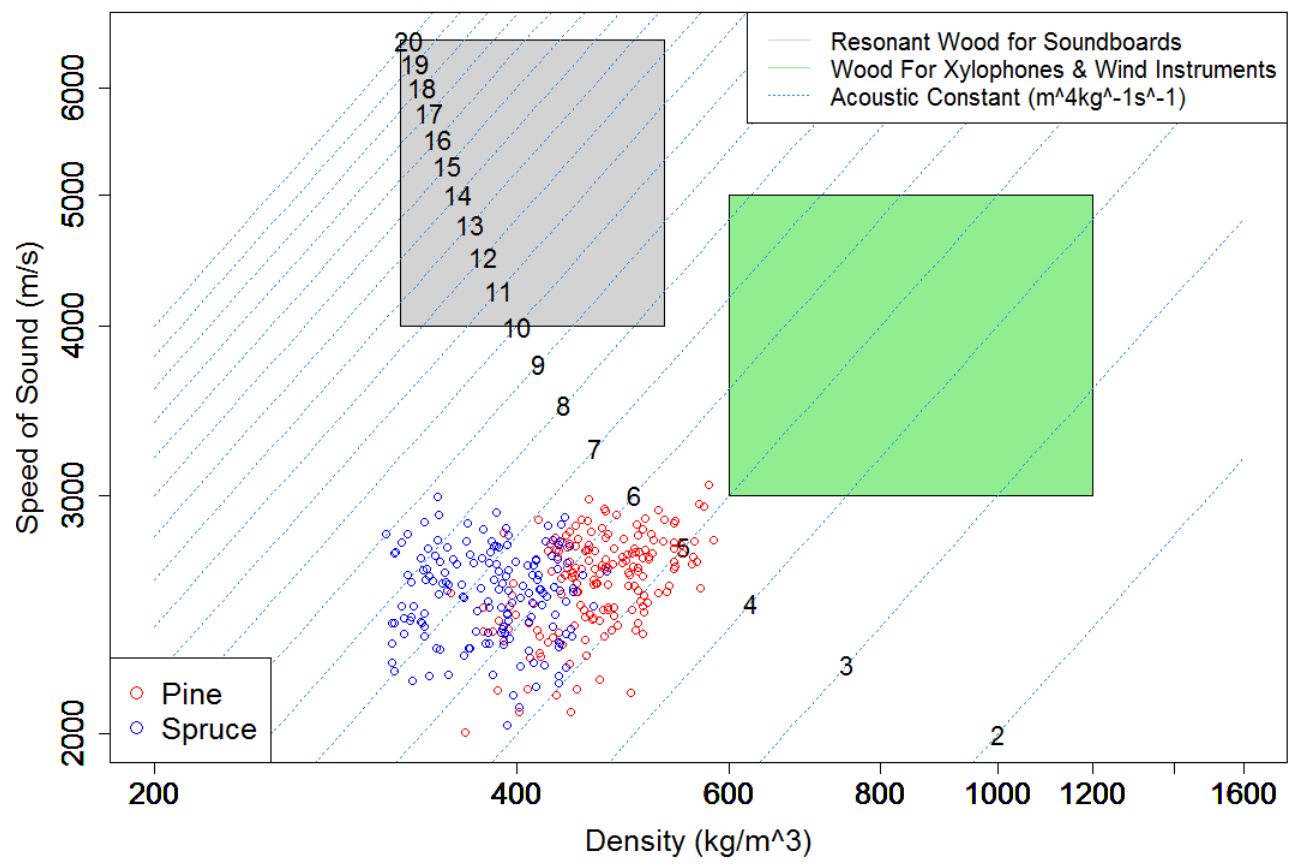

(a)

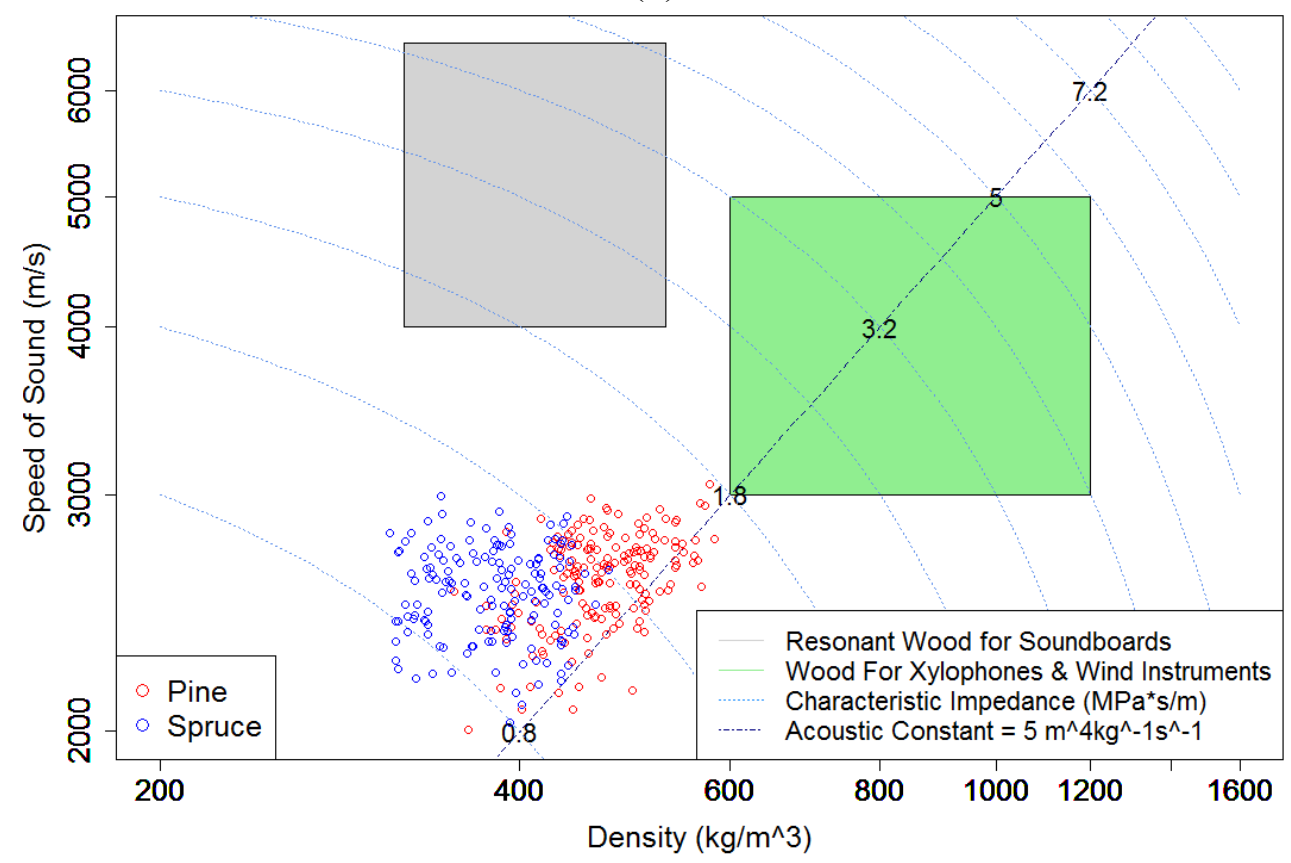

(b)

Examining the data for $\rho, c, A C$ and $Z$ (Figure 2), the changes to $A C$ were caused primarily by changes in density; that is, small changes in density lead to larger changes in $A C$. The speed, however, remained constant throughout and did not cause large variations in $A C$. This was supported by the fact that the speed of sound through wood was dependent on the density. 
The dependence of $A C$ on $\rho$ can be further demonstrated by comparing changes in the $A C$ and $\rho$ for each disk individually. It was observed that the $A C$ responded inversely to changes in the $\rho$. The same dependence was not seen when examining the acoustic constant against the speed of sound in the wood; the acoustic constant fluctuates independent of changes to the speed of sound through the wood.

The main impact that the speed of sound holds over $A C$ was in its overall magnitude. When the speed of sound was high, in addition to having a low density, such as disk 10, this resulted in a much higher $A C$. The lower than average speed of sound was most likely the cause of the lower than average acoustic constant values compared to resonant woods.

Figure 2. Comparison of physical acoustic characteristics.

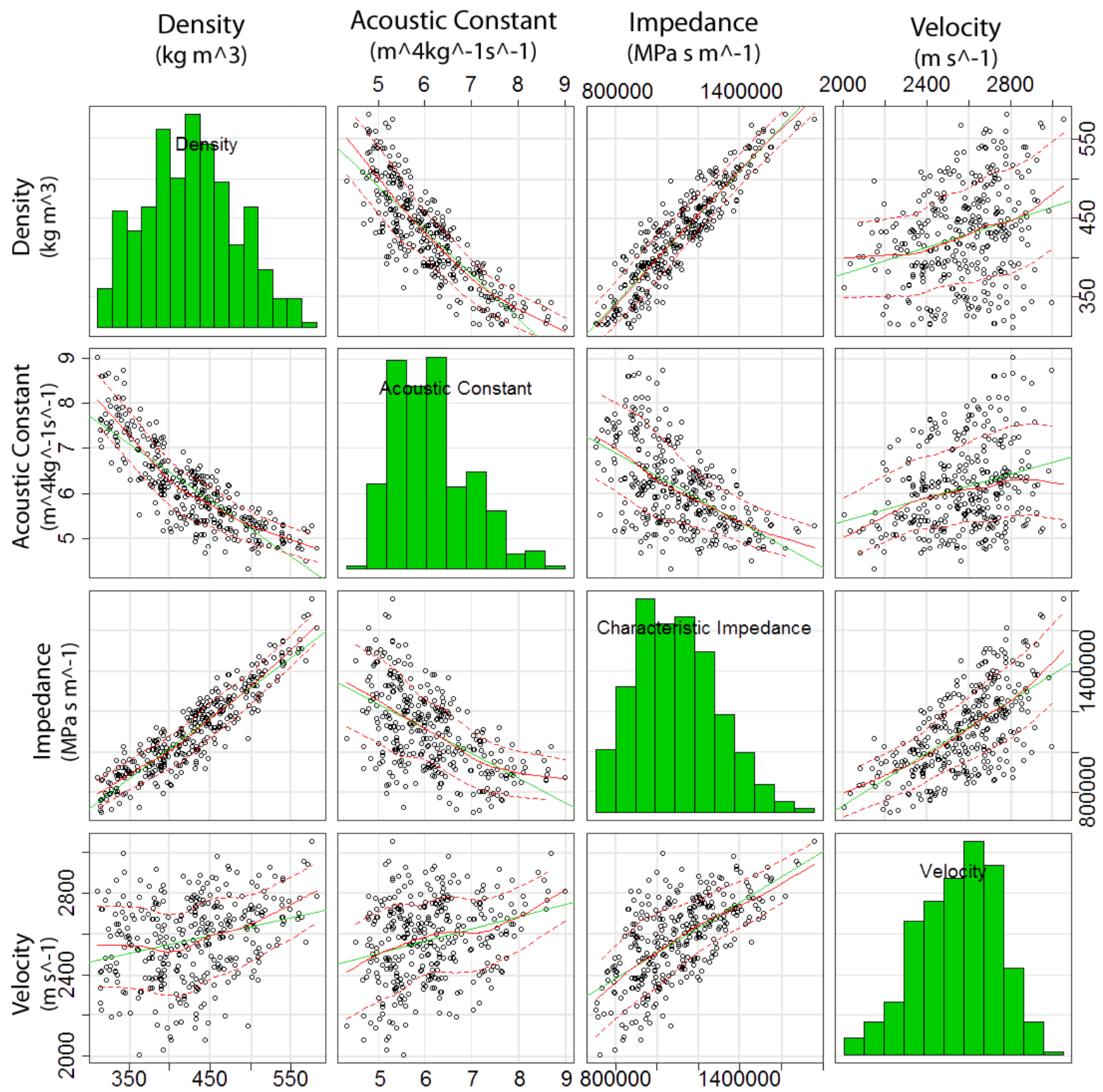

\section{Experimental Section}

Submerged trees were removed from Ootsa Lake, British Columbia, Canada $\left(53.7500^{\circ} \mathrm{N}\right.$, $126.0333^{\circ} \mathrm{W}$ ) in late summer 2006 ; the trees were submerged in fresh water in 1952 after the damming of a local river. The logs from the trees were identified as lodgepole pine (Pinus contorta.) and interior 
spruce (Picea spp.), which is a hybrid species of Englemann spruce (Picea engelmannii) and white spruce (Picea glauca). The average age of the trees was 133 years [2], prior to flooding.

Pine logs were numbered 1-5, 7 and 12 and spruce logs were numbered 6, and 8-11. One disk was removed from the upper part of each log and 70-mm thick disks were cut. Disks 1-5, 7 and 12 were pine and disks 6, 8-11 were spruce. From each disk, 35-40 samples were cut $[2,14]$ with approximate dimensions of $55 \mathrm{~mm} \times 15 \mathrm{~mm} \times 15 \mathrm{~mm}$, ensuring samples were free of defects and knots based on visual inspection. For the 2007 experimental measurements, the samples were dried in a convection oven until an equilibrium moisture content, $E M C$, of $12 \%$ was reached (determined by matched samples and by weighing to constant weight). For the 2010 experimental measurements, no additional preparation of the samples was performed except that they were stored untouched in laboratory conditions $\left(20^{\circ} \mathrm{C}, \sim 35 \%\right.$ relative humidity) achieving an $E M C$ of $\sim 6 \%$.

A Metriguard Stress Wave Tester (Model 239) with a pendulum steel-ball apparatus was used. Five repeated measurements were taken for each sample. The length of wood, $l(\mathrm{~m})$, that the sound wave travelled was measured and, together with average time, $t_{\text {ave }}(\mathrm{s})$, the average speed of sound, $c_{\text {ave }}\left(\mathrm{m} \cdot \mathrm{s}^{-1}\right)$ through wood was determined:

$$
c_{\text {ave }}=\frac{l}{t_{\text {ave }}}
$$

Wood density $\rho_{M C}\left(\mathrm{~kg} \cdot \mathrm{m}^{-3}\right)$ is an important material property related to acoustic characteristics [1], and is calculated by:

$$
\rho_{M C}=\frac{m_{M C}}{V_{M C}}
$$

where $m_{M C}$ is mass $(\mathrm{kg})$ and $V_{M C}$ is volume $\left(\mathrm{m}^{3}\right)$ at a given moisture content, $M C(\%)$.

Two acoustic measurements, the characteristic impedance and acoustic constant, were determined by the combination of sound speed and wood density. The acoustic constant, $A C\left(\mathrm{~m}^{4} \cdot \mathrm{kg}^{-1} \cdot \mathrm{s}^{-1}\right)$, is a measure of the vibration within the wood as it is damped by radiating sound [1] determined by:

$$
A C=\frac{c}{\rho}
$$

Wood impedance $Z\left(\mathrm{~Pa} \cdot \mathrm{s} \cdot \mathrm{m}^{-1}\right)$, is a vibration-propagation measurement between media such as from the soundboard of an instrument to the resonator [1] and is determined by:

$$
Z=c \cdot \rho
$$

The average, standard deviation and error in the average were determined using:

$$
\bar{x}=\frac{1}{n} \cdot \sum_{i=1}^{n} x_{i}
$$

where $x$ is the arithmetic mean, $x_{i}$ is the $i^{\text {th }}$ measurement and $n$ is the number of measurements taken;

$$
\sigma_{s d}=\sqrt{\frac{1}{n} \cdot \sum_{i=1}^{n}\left(\bar{x}-x_{i}\right)^{2}}
$$

is the standard deviation; and the error of the mean is found with: 


$$
\delta x=\frac{\sigma s d}{\sqrt{n}}
$$

To statistically compare sets, Welch's two sample t-statistic test was chosen due to the unequal variance between some sets and the sets being unpaired. The t-statistic ( $t$-stat) was calculated using:

$$
t \text { stat }=\frac{\overline{x_{1}}-\overline{x_{2}}}{\sqrt{\frac{s_{1}{ }^{2}}{n_{1}}+\frac{s_{2}{ }^{2}}{n_{2}}}}
$$

where $x_{1}$ and $x_{2}$ are the sample means; $s_{1}{ }^{2}$ and $s_{2}{ }^{2}$ are the sample variances; and $n_{1}$ and $n_{2}$ are the sample sizes for the first and second samples, respectively. The degrees of freedom, $v$, for Welch's two sample t-statistic test is found using:

$$
v=\frac{\left(\frac{s_{1}{ }^{2}}{n_{1}}+\frac{s_{2}{ }^{2}}{n_{2}}\right)}{\frac{s_{1}{ }^{4}}{n_{1}{ }^{2} \cdot\left(n_{1}-1\right)}+\frac{s_{2}{ }^{4}}{n_{2}{ }^{2} \cdot\left(n_{2}-1\right)}}
$$

\section{Conclusions}

After an initial study performed on submerged wood revealed that the wood was not suitable for use as musical instruments, the wood was left untouched in a laboratory environment. It was believed that the physical acoustic properties of the wood, such as the density, speed of sound and, consequently the acoustic constant and characteristic impedance, would improve with aging and drying. In this study, the acoustic properties of the submerged wood, however, did not improve and instead became less desirable.

The characteristic impedance and acoustic constant of the submerged wood was compared with that of normal values for resonant wood used in soundboards, xylophones and wind instruments. It was found that a few spruce samples were within the minimum range required for the acoustic constant of soundboards but this was not the case for the characteristic impedance. Pine samples, however, had an appropriate characteristic impedance for soundboards but did not have an appropriate acoustic constant.

Both pine and spruce samples were within the acceptable range of values for acoustic constants for use in xylophones and woodwind instruments but did not have appropriate characteristic impedance. While the speed of sound was adequate for these types of instruments, both xylophones and woodwind instruments require a higher density which the submerged wood samples did not have.

\section{Acknowledgments}

The authors would like to acknowledge former MSc graduate students Ben Woodward, Sorin Pasca, Tara Todoruk and the staff in the Ike Barber Enhanced Forestry Lab at UNBC for technical assistance with this study. The author (IDH) acknowledges support from the Natural Sciences and Engineering Research Council of Canada (Discovery Grant Program).

\section{Author Contributions}

The manuscript was based on research work done by Calvin Hilde and Renata Woodward for their academic degrees at UNBC. The experimental design, writing of the manuscript (along with Calvin Hilde) 
and supervision was done by Ian Hartley; Calvin Hilde and Renata Woodward provided literature review, sample preparation coordination, data gathering and analysis; Stavros Avramidis provided the equipment, laboratory space, expertise and final editing of the manuscript.

\section{Conflicts of Interest}

The authors declare no conflict of interest.

\section{References}

1. Wegst, U.G. Wood for sound. Am. J. Bot. 2006, 93, 1439-1448.

2. Woodward, R. The Acoustic Properties of Submerged Wood and Their Potential for Musical Instrument Making. Bachelor's Thesis, University of Northern British Columbia, Prince George, BC, Canada, July 2007.

3. Parfitt, L.J.; Hartley, I.D.; Avramidis, S. Acoustic constant property of Interior spruce (Picea spp.) from the central interior of British Columbia. For. Prod. J. 2005, 55, 74-76.

4. Akitsu, H.; Norimoto, M.; Morooka, T.; Rowell, R.M. Effect of humidity on vibrational properties of chemically modified wood. Wood Fiber Sci. 1993, 25, 250-260.

5. Buksnowitz, C.; Teischinger, A.; Müller, U.; Pahler, A.; Evans, R. Resonance wood [Picea abies (L.) Karst.]—Evaluation and prediction of violin makers' quality-grading. J. Acoust. Soc. Am. 2007, 121, 2384-2395.

6. Jansson, E. Applied acoustics. In Acoustics for Violin and Guitar Makers, 4th ed.; KTH Royal Institute of Technology: Stockholm, Sweden, 2002.

7. Hacker, J.J. Evaluation of Niche Markets for Small Scale Forest Products Companies. Available online: http://dnr.wi.gov/topic/ForestBusinesses/documents/NicheMktsForestProducts.pdf (accessed on 6 March 2012).

8. Recovered Old Growth Timber. Available online: http://www.desertrosebanjo.com/oldwood.html (accessed on 28 March 2012).

9. Chan, J.M. Moisture Content in Radiata Pine Wood: Implications for Wood Quality and Water-Stress Response. Ph.D. Thesis, University of Canterbury, Christchurch, New Zealand, 2007.

10. Wegst, U.G. Bamboo and Wood in Musical Instruments. Ann. Rev. Mater. Res. 2008, 38, 323-349.

11. Bucur, V. Acoustics of Wood, 2nd ed.; Timell, T.E., Wimmer, R., Eds.; Birkhäuser: Berlin, Germany, 2006.

12. Onda Corporation Acoustic and Ultrasound Testing Products and Services. Available online: http://www.ondacorp.com/images/Solids.pdf (accessed on 6 March 2012).

13. Gonzales, J.S. Wood Density of Canadian Tree Species; Forestry Canada, Northwest Region, Northern Forestry Centre: Edmonton, AB, Canada, 1990.

14. Ličko, J. On using the sycamore wood in the manufacturing of violins. Drev. Výsk. 2000, 45, 23-31.

(C) 2014 by the authors; licensee MDPI, Basel, Switzerland. This article is an open access article distributed under the terms and conditions of the Creative Commons Attribution license (http://creativecommons.org/licenses/by/3.0/). 